\title{
Licorice cream promotes full-thickness wound healing in Guinea pigs
}

\author{
Nafise HANAFI ${ }^{1,2}$, Fereshteh TALEBPOUR AMIRI ${ }^{1}$, , Somayeh SHAHANI ${ }^{3}$, Reza ENAYATIFARD ${ }^{4}$, \\ Maryam GHASEMI ${ }^{5}$, Abbas Ali KARIMPOUR ${ }^{1}$
}

1 Department of Anatomy, Faculty of Medicine, Molecular and Cell Biology Research Center, Mazandaran University of Medical Sciences, Sari, Iran.

2 Student Research Committee, Faculty of Medicine, Mazandaran University of Medical Sciences, Sari, Iran.

3 Department of Pharmacognosy and Biotechnology, Faculty of Pharmacy, Mazandaran University of Medical Sciences, Sari, Iran.

4 Department of Pharmaceutics, Faculty of Pharmacy, Mazandaran University of Medical Sciences, Sari, Iran.

5 Department of Pathology, Faculty of Medicine, Mazandaran University of Medical Sciences, Sari, Iran.

* Corresponding Author. E-mail: ftaleb2001@yahoo.co.uk (F.T.A.); Tel. +981133543088; ORCID No: 0000-0002-42367439

Received: 06 December 2017 / Revised: 13 February 2018 / Accepted: 18 February 2018

\begin{abstract}
Impaired wound healing may cause economic and social problems and seriously reduce the quality of life. The uses of herbal medicines as new alternative treatments are under investigation. This study investigated the effect of Glycyrrhiza glabra L. extract on the full-thickness wound healing in Guinea Pig model. Eight male Guinea Pigs $(700-800 \mathrm{~g})$ were used to be creared a square full-thickness wound with $1.5 \times 1.5$ dimensions on the lumbodorsal area. The wounds were randomly divided into four groups: I; control, II; 1\% phenytoin, III; $\%$ G. glabra and IV; $10 \%$ G.glabra. On day 3, 5, 7, 9 and 12, wound size was measured for assessment of the percent of wound healing. In order to determine the wound healing activity, excisional biopsies were evaluated histopathologically on the 12th days of treatments. Acute inflammation, granulation tissue fibroblast maturation, collagen deposition, epidermal layer formation, neovascularization, keratin layer formation were evaluated according to the Abramov score method. Hydroalcoholic extract of G.glabra exhibited total phenolic and flavonoid contents of $114.1 \pm 5.45$ and $82.85 \pm 6.38$ mg, respectively. G.glabra creams ( $5 \%$ and $10 \% \mathrm{w} / \mathrm{w}$ ) were significantly increased the epidermal formation, collagen deposition and neovascularization, and was decreased acute inflammation in comparison to the control group. Wound healing rate were increased in the G. glabra groups. G.glabra creams $10 \%$ was more effective than $5 \%$ w/w. Our findings proved that $5 \%$ and $10 \% \mathrm{w} / \mathrm{w}$ G. glabra creams were effective in acute dermal wound healing. More studies with different doses of G. glabra extract are recommended.
\end{abstract}

KEYWORDS: Glycyrrhiza glabra L.; dermal wound healing; flavonoid, phenol; Guinea pigs models.

\section{INTRODUCTION}

Wound healing, a physiological process, is repair of damaged cells and tissues that occurs with an accurate and properly process. Phases of wound healing includes: hemostasis, inflammation, proliferation, and remodeling, which that overlap with each other [1]. Loss of skin integrity by trauma leads to an imbalance of hemostasis and so, wound healing process become impaired [2]. Dermal wounds are a major concern and seriously reduce the quality of life for patients. As well, dermal wounds, with high cost and an inert treatment is a public health problem [3]. So, trying to quickly close the cutaneous wound with functional and aesthetic results would be ideal goal of treatment [4]. On the other hand, impaired wound healing is the main source of mortality and morbidity, that is associated with high costs [5]. Natural products are safe, less side effect, cultured acceptability and with having excellent physiological properties are the source of new treatments for cutaneous wound healing [6]. Herbal drugs are inexpensive compared with synthetic drugs. So some researchers have focused on the potential healing properties of herbs and there are various reports on using herbal drugs in healing of skin injuries [7, 8].

Glycyrrhiza glabra L. (G. glabra, Licorice), a native of south-east Europe and south-west Asia , is one of the most widely used as a herbal medicine, natural sweetener, as an additive for flavoring and sweetening

How to cite this article: Hanafi N, Talebpour Amiri F, Shahani S, Enayatifard R, Ghasemi M, Karimpour AA. Licorice cream promotes full-thickness wound healing in Guinea pigs. Marmara Pharm J. 2018; 22 (3): 411-421. 
tobacco, candies, and beverages [9] and skin-cosmetics [10]. Pharmaceutical therapeutic properties, such as antifungal [11] and antimicrobial [12] efficacy, antiviral and antitumoral activity [13], anti-bacterial [14], antioxidant [15], antiulcer [16] have been reported in the numerous articles, that are only some of possible therapeutic properties. The main biologically active components of licorice include: triterpene saponins, flavonoids, isoflavonoids, chalcones and glycyrrhizic acid which are responsible for the observed activities $[17,18]$. G. glabra is a medicinal plant that abundantly used in ancient times for treat bacterial and fungal infections but so far only one study reported the wound healing activity of this plant on full-thickness dermal wound in rat model [19]. Studies have shown that G. glabra can have a role in wound healing of gastric [20], oral [21] and colitis [16] mucosal ulcers. Also, the extract of this plant was effective on burning wound healing [22]. Since pig skin is similar to human skin physiologically and anatomically [23], and based on above facts about the G. glabra properties, this study was conducted to evaluate the effects of G. glabra on full thickness wound healing in guinea pigs.

\section{RESULTS}

\subsection{Total phenolic and total flavonoid contents}

The total phenolic and total flavonoid contents of the extract were $114.1 \pm 5.45 \mathrm{mg}$ gallic acid equivalents and $82.85 \pm 6.38 \mathrm{mg}$ quercetin equivalents per gram dried extract respectively.

\subsection{Macroscopic observation of wound healing}

All animals studied survived in the surgical procedures and during study period without any complications. Symptoms of secondary infection were not observed in any wounds. Wound surface in the phenytoin and G. glabra groups were moist. In macroscopic observation, necrotic tissue covers most of the surface of the wound in control group and clearly became visible on the wound areas from the early days in the control group, while necrotic tissue was not seen on wounds in the treated groups. New epithelium was totally obvious at the edges of the wound with a pinkish color in the treatment (phenytoin and G. glabra) groups (Figure 1).

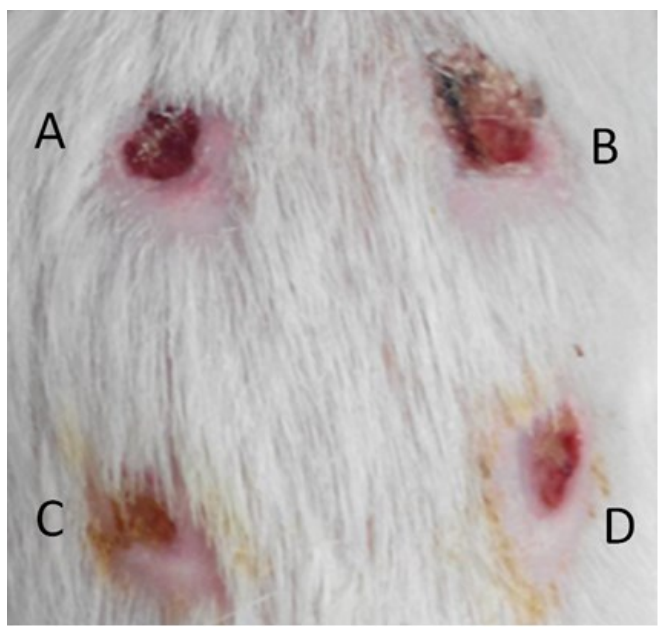

Figure 1: Macroscopic morphology of the wound healing in groups after 12- day treatment by application of G. glabra cream. A) control, B) phenytoin, C) $5 \%$ and D) $10 \%$ G. glabra cream. The ratios of wound areas to the initial wound area (WHR\%) were greater in the treatment group compared with the control group.

\subsection{Wound healing rate findings}

Figure 2 shows the wound healing rate (WHR) in the groups. The ratios of wound areas to the initial wound area on days 3, 5, 7, 9 and 12 were calculated. In the 5\% G. glabra group, the wound area decreased and scare of wounds healed on day 12, being smaller in wound area than other groups. Difference between groups was statistically significant. As shown in Table 1 , until the $5^{\text {th }}$ day, the average of WHR in the groups was seen a similar increase. The mean WHR in wound area were presented in figure 2. Consider the following graph: 


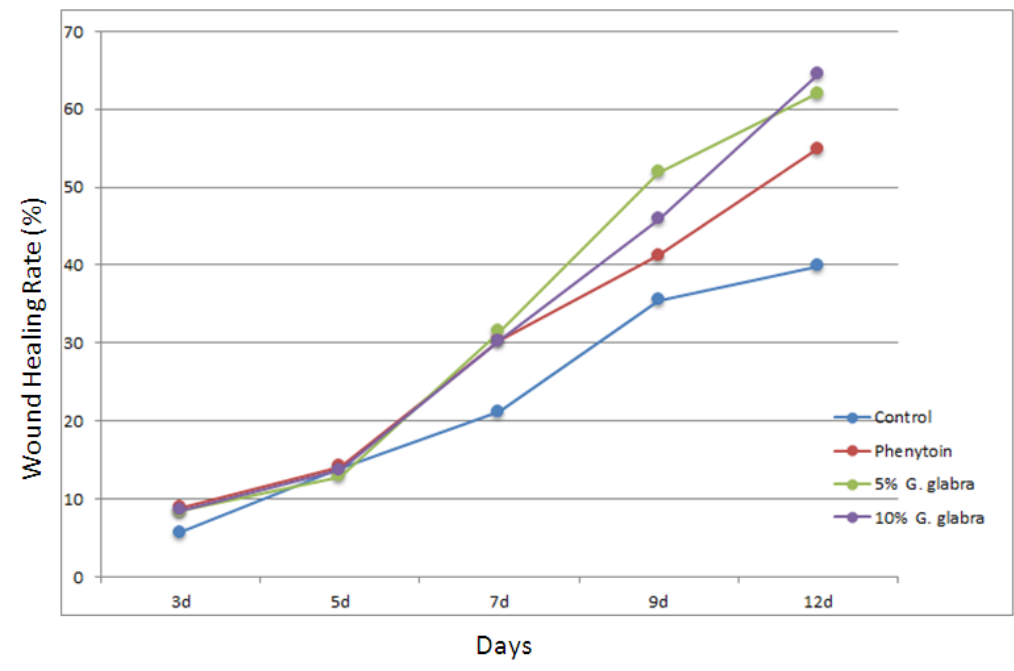

Figure 2: The ratios of wound areas to initial area on days 3, 5, 7, 9 and 12 were drawn on a line graphs. There were significant differences between the treatment groups with control groups. In all groups, the WHR increased gradually until day 5 during the inflammatory phase and the proliferative phase, increased with more speed until day 12 in the phenytoin and G. glabra groups during the remodeling phase and it was a gradual increase in the control groups $(P<0.05)$.

As was shown in Table 1, there was significant difference in WHR between G. glabra groups with control group regarding the wound healing score determined by microscopic analysis of wounds. The most important changes that can be seen from the image are the formation of epidermis after G. glabra cream treatment compared to control group. G. glabra stimulated epithelialization. New epidermis in 5 and 10\% G. glabra covered 62.02 and $64.5 \%$ respectively, of the wound surface on day 12, while in the control and phenytoin groups, new epithelium covered 39.86 and $54.89 \%$ of the surface of the wound, and these differences were statistically significant in G. glabra groups compared with control group. G. glabra stimulated epithelialization, and seemed that is not dose-dependent. Analysis of WHR is showed in the table 1.

Table 1. WHR during days 3, 5, 7, 9 and 12 after the wound creation.

\begin{tabular}{llllll}
\hline WHR/Groups & $\begin{array}{l}\mathbf{3}^{\text {th }} \text { day } \\
\text { Mean } \pm \text { SD }\end{array}$ & $\begin{array}{l}\mathbf{5}^{\text {th }} \text { day } \\
\text { Mean } \pm \text { SD }\end{array}$ & $\begin{array}{l}\text { 7th }^{\text {day }} \\
\text { Mean } \pm S D\end{array}$ & $\begin{array}{l}\mathbf{9}^{\text {th }} \text { day } \\
\text { Mean } \pm S D\end{array}$ & $\begin{array}{l}\mathbf{1 2}^{\text {th }} \text { day } \\
\text { Mean } \pm S D\end{array}$ \\
\hline Control & $5.7 \pm 2.55$ & $13.84 \pm 5.61$ & $21.15 \pm 8.23$ & $35.44 \pm 9.56$ & $39.86 \pm 8.27$ \\
Phenytoin & $8.84 \pm 2.26^{a}$ & $14.15 \pm 1.94$ & $30.37 \pm 7.75$ & $41.24 \pm 10.23$ & $54.89 \pm 9.85^{a}$ \\
$5 \%$ cream & $8.41 \pm 1.6$ & $12.83 \pm 1.51$ & $31.52 \pm 11.49$ & $51.9 \pm 9.91^{a}$ & $62.02 \pm 9.74^{a}$ \\
$10 \%$ cream & $8.54 \pm 1.23^{a}$ & $13.68 \pm 1.4$ & $30.3 \pm 3.73 a^{a}$ & $45.86 \pm 6.23$ & $64.5 \pm 11.83^{a}$ \\
\hline
\end{tabular}

Control; without any prescription, Phenytoin; wounds treated with $1 \%$ phenytoin, $5 \%$ cream; wounds treated with 5\% G. glabra cream, $10 \%$ cream; wounds treated with $10 \%$ G. glabra cream. a significant $\mathrm{P}<0.05$ versus control. WHR expressed in $\mathrm{cm}^{2}$ mean \pm S.D. WHR; Wound Healing Rate

\subsection{Microscopic Observation}

Figure 3 has been shown the photomicrographs of the wound area in different groups that taken 12 days after the wound creation. The histopathological findings showed the granulation tissue formation, keratin, neoepiderm and neovascularization are marked. Each wound was given a score from 0 to 3 and a mean score was calculated in each group. Then the average scores of wound healing criteria were compared for each group.

Wound healing mean scores of all groups are presented in Figure 4 . The number of macrophages and neutrophils were counted on day 12 in each group. The inflammatory cell infiltration in the control group was significantly larger than the G. glabra and phenytoin groups ( $P<0.05$ and $P<0.01$, respectively). The number of macrophages in the phenytoin and $5 \%$ and $10 \%$ G. glabra groups no difference was seen.

In this study, the G. glabra cream induced fibroblast cell proliferation in wound area. The amount of granulation tissue increased significantly on 12 days in phenytoin and G. glabra groups. Granulation tissue filled the wound space. Maturation of granulation tissue increased in 5\% and 10\% G. glabra group compared 
with control and phenytoin groups. Besides that, maturation of granulation tissue was increased on 12 day in phenytoin compared with control group.
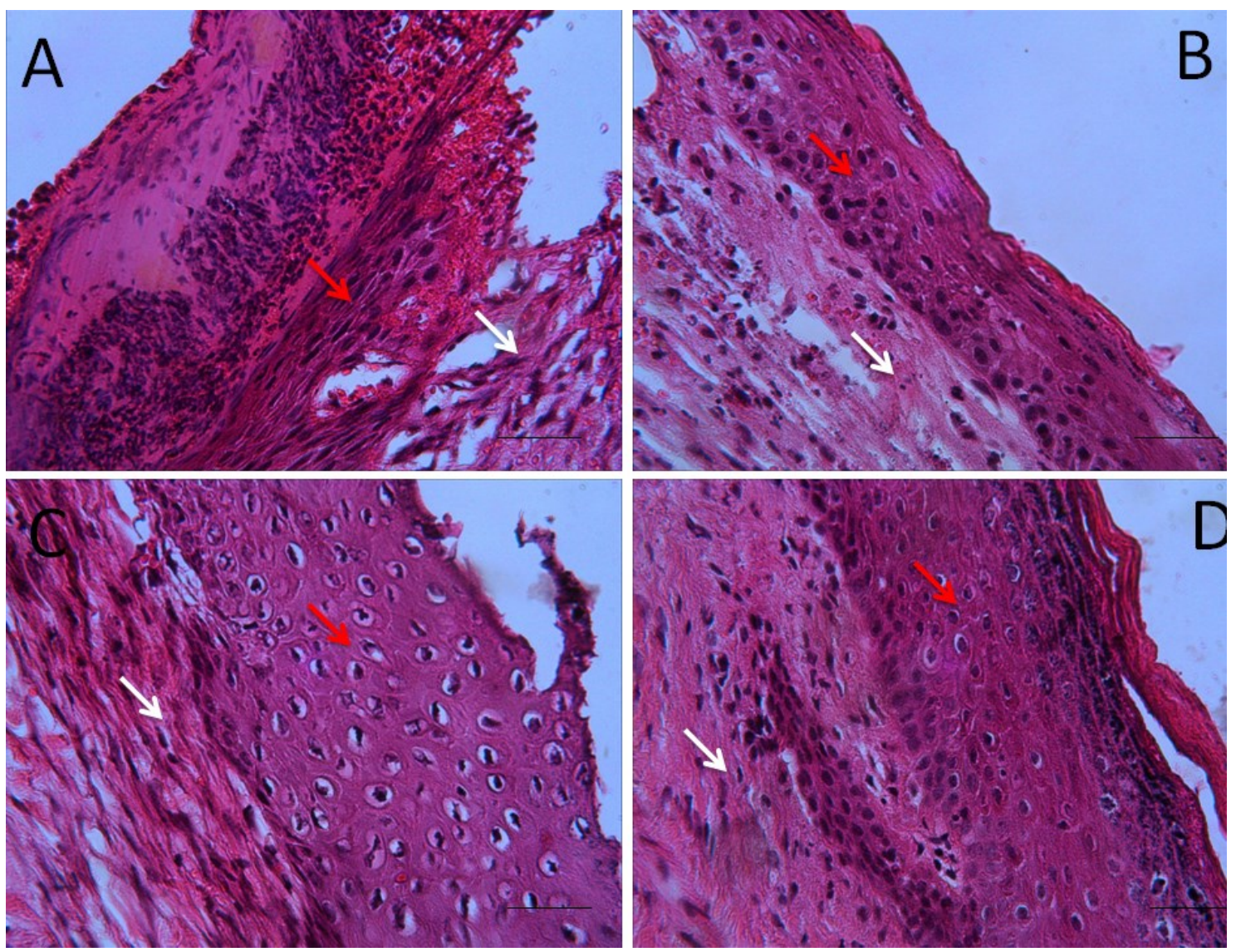

Figure 3. Photomicrographs of the biopsy specimens taken from the Guinea Pig 12 days after the surgery. A more perfect epidermis layer (red arrow) can be seen G. glabra cream treatment in acute wound models. The granulation tissue formation (white arrow) and keratin layer formation is clearly seen in treated groups. G. glabra cream was effective in formation of the granulation tissue, new epiderm and keratin layer compared with the control group, and this difference was significant $(\mathrm{P}<0.05)$. $\mathrm{H} \& \mathrm{E}$. Mag; $\times 40$. Scale bar $=$ $100 \mu \mathrm{m}$.

Keratin layer formation, as a key role in the wound healing process in the skin surface, was appeared in the G. glabra groups. Furthermore, G. glabra cream caused the formation of epidermal and keratin layer compared with control and phenytoin groups $(P<0.05)$. Phenytoin increased keratin layer formation, but not significant compared with control group.

The number of new blood vessels per HPF $\times 40$ in the G. glabra and phenytoin groups increased rapidly. G. glabra and phenytoin stimulated angiogenesis, and this increase was significant compared with control group. In addition, it can be prove that G. glabra cream treatment induced neovascularization greatly in the dermis layer.

The collagen fibers stained with Trichrome Masson colored in blue (Figure 5). The content collagen deposition in the granulation tissue in the wound area increased in all groups, but in the $5 \%$ and $10 \%$ G. glabra groups were larger than control group $(P \leq 0.03, P \leq 0.03$, resp.). There was no significant difference in collagen fiber deposition between the two treatment groups. The amount of collagen fibers in the G. glabra groups were more than in the phenytoin group. Evaluation by Mac Biophotonics Image J 1.41 software showed a 50\% increase between the two treatment groups compared phenytoin and control groups. 

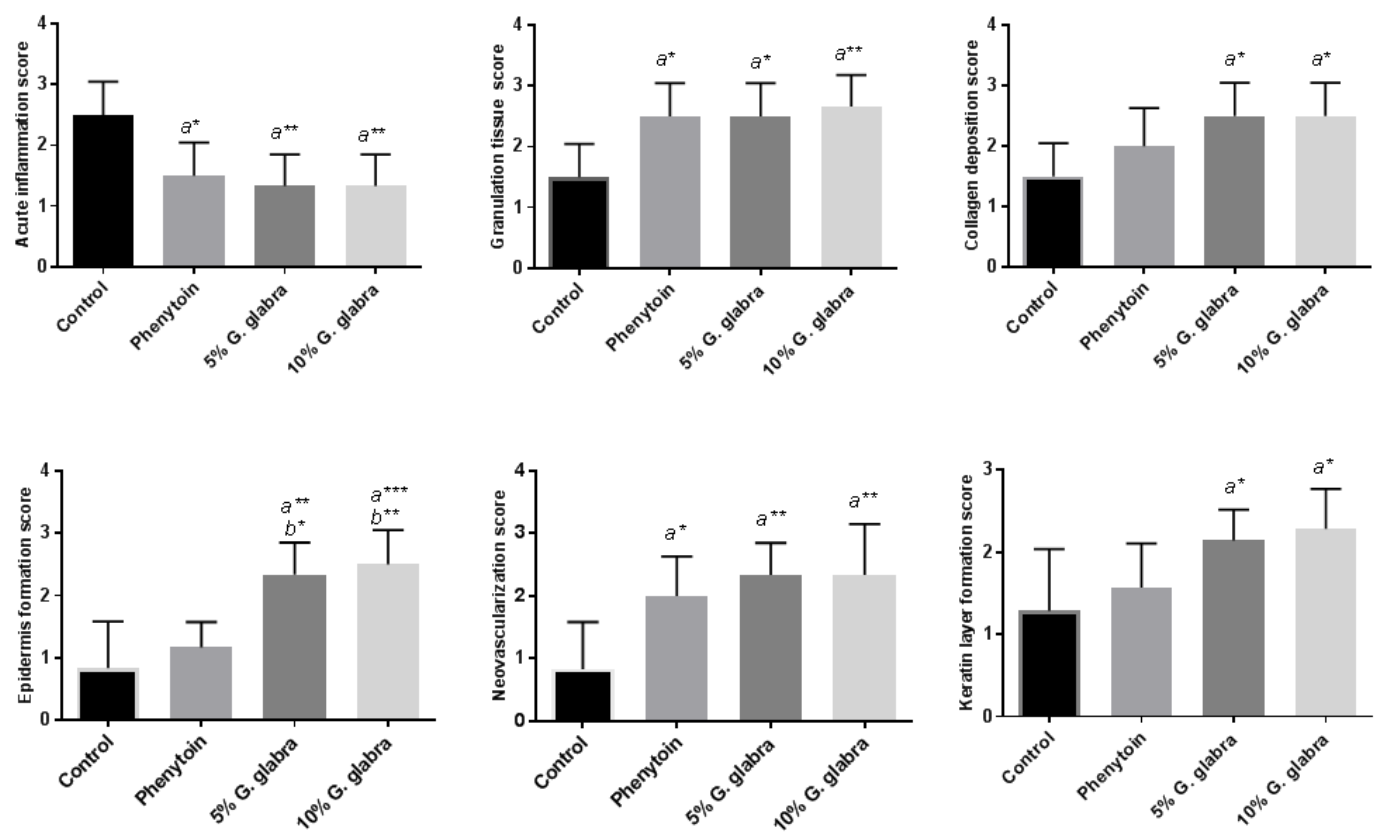

Figure 5. Guinea Pigs were treated with G. glabra showed an increase in the wound healing mean scores compared with control group $(\mathrm{P}<0.05)$. All values are expressed as mean $\pm \mathrm{SD}$. a significant versus control group and $b$ significant versus phenytoin group. *; $P \leq 0.05,{ }^{* *} ; P \leq 0.01$ and ${ }^{* *}$. G. glabra; Glycyrrhiza glabra
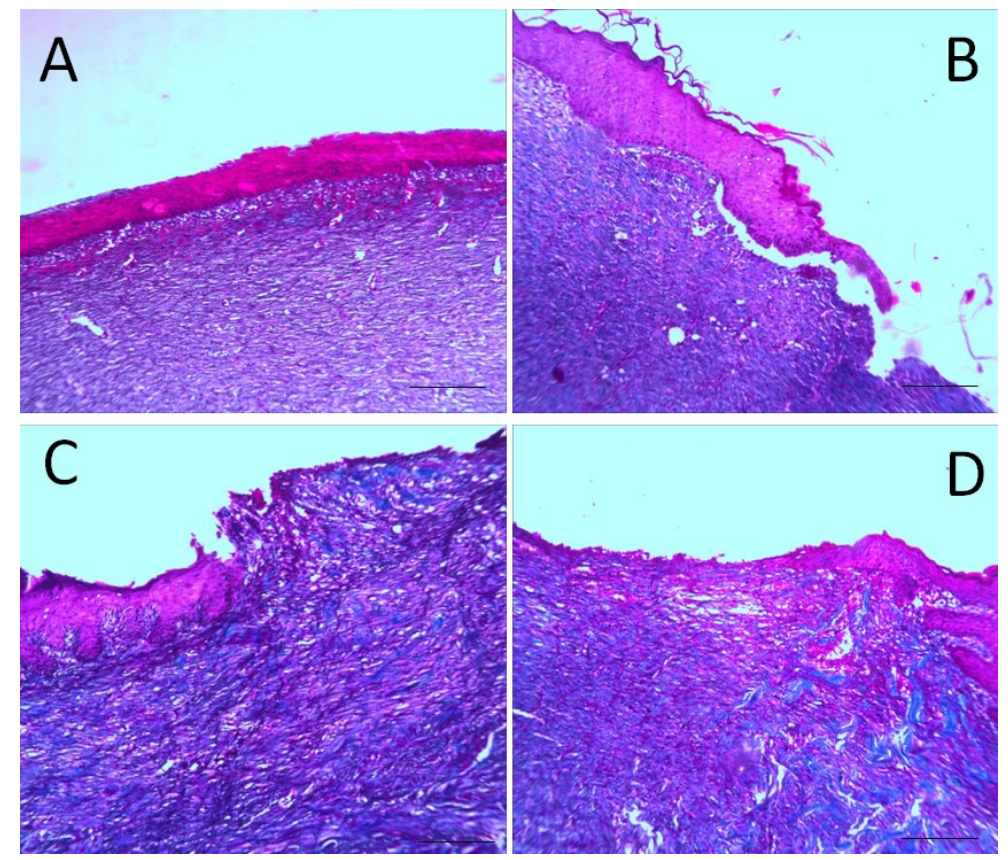

Figure 5. Histopathology of acute wound healing and the amount of collagen deposition at 12th day of the study. A; control, B; 1\% Phenytoin, C; 5\% G. glabra cream, D; 10\% G. glabra cream groups. The amount collagen deposition in the granulation tissue in the wound area increased in all three treatment groups compared with the control group. Masson's Trichrome staining, Magnification; $\times 10$. Scale bar $=100 \mu \mathrm{m}$.

\section{DISCUSSION}

Healing process is a natural response and do not need to help. But impaired wound healing have helped to promote this process [24]. In the present study, macroscopic study of the cream treated groups also showed the effectiveness of G. glabra in improved wound healing. We showed that topical application of G. glabra cream accelerates wound healing in acute wound model. There were statistically significant differences in histological criteria between the groups. The top score fibroblast maturation, granulation tissue formation, proliferation of fibroblasts, dermal and epidermal regeneration and enormous angiogenesis, increased WHR 
and collagen synthesis and decreased inflammation in the wound area in G. glabra treated (5\% and $10 \%)$ groups confirmed with histological evaluation.

In present study, G.glabra creams increased significantly the WHR rate compared with the control group. Proliferation of epithelial cells and epidermal formation increased the WHR in wounds treated with G. glabra. We evaluated the mean WHR till the $12^{\text {th }}$. In contrast to our findings, Oloumi et al indicated that G.glabra are able to be effective in the wound healing in rats, but not effective on wound healing rate. This researcher showed wounds treated with G. glabra are associated with less wound closure. They have created fullthickness wound with $7 \mathrm{~mm}$ diameter and were treated for 7 days. Also, they used G.glabra in the form of an extract [19]. While in this study, we have created wound with $1.5 \times 1.5 \mathrm{~cm}^{2}$ dimensions and after 12 days were checked. Also, G.glabra was prescribed cream form. Increased of WHR rate in treatment wounds can be related to increased re-epithelialization in treated wounds and the presence of flavonoids compounds. Flavonoids to inhibit or reduce cell necrosis plays a role in increasing the synthesis of DNA [25]. In this study, necrotic tissue clearly evident in control group and G. glabra cream treatment improved cell proliferation and regrowth of the epidermis.

In this study, we evaluate the level of collagen deposition with Masson trichrome staining that reveal that collagen deposition of the granulation tissue in treated groups with $5 \%$ and $10 \%$ cream was significantly increased when compared to the control groups $(\mathrm{P}<0.05)$. These findings may be related to the presence of flavonoids. Both concentrations of the creams studied have the same effect on collagen synthesis. Collagen, a key protein in the extracellular matrix of granulation tissue, considerably contributes in wound strength [26]. Flavonoids increase the synthesis and cross-linking of collagen and on the other hand, decrease the degradation of collagen solution [27]. In the present study, quantitative analysis of the extract revealed the high levels of total phenolic and flavonoid contents in the roots of G. glabra. Recent studies have shown the role of flavonoids in the promotion of wound healing [28]. As well Glycyrrhizin (Gly) and a -and $\beta$ glycyrrhetinic acids isolated from G. glabra, cause to increase collagen content and the subsequent wound healing [22]. Topical phenytoin with having antibacterial activity and preventing secondary wound infections, accelerated excisional wound healing [29]. In this study, G G. glabra cream stimulated the synthesis of collagen in the dermis layer.

Data showed the topical application of G. glabra by having anti-inflammatory properties and by control of inflammation improved the wound healing process and prevented the secondary wound infections $(\mathrm{P}<0.01)$. Inflammation is a biological response to a stimulus, such as trauma that causes the production reactive oxygen species (ROS) [30]. Inhibit of the inflammatory phase cause restored the damaged tissue. Gly as a triterpenoid saponin glycoside, is an active component of G. glabra root that at concentrations of $7-10 \%$ in the body is converted to glycyrrehetic acid (GA). Anti-inflammatory properties of G. glabra is related to GA. GA by inhibiting the activity of proinflammatory prostaglandins and leuktrienes (as inflammatory mediators), is as an anti-inflammatory [31]. Evans et al showed Gly with having anti-inflammatory properties was improved subacute and chronic dermatoses [32]. Also Gly, with the production of interleukin-1 (IL-1), IL-2, and IL-12 increase antibody production [33]. Interleukin-2, as a cytokine with effect on the T-cell, has a key role in wound healing [5]. It was shown that G. glabra, is effective for the treatment of skin diseases such as dermatitis, eczema and psoriasis. Glycyrrhizin by inhibiting local inflammatory pathogens treat skin injuries [34].

HMGB1, as an early mediator of inflammation, increase in traumatic injury and plays a cytokine-like in burn injury [35]. This mediator affect in angiogenesis and wound healing [36]. Shen et al, in their studies showed that administration of Gly before and after burn via intraperitoneal significantly improved thermal skin injury [35]. Gly, with reduction in serum inflammatory factors (TNF-a, IFN- $\gamma$, IL-6, IL-1b , and IL-17) and the increase in HMGB1 protein/mRNA expression from damaged cells is effective in wound healing [36]. So, G. glabra significantly mitigated thermal injury. This study is consistent with the our investigation, but in study of Tanideh et al 10\% licorice extract were used and there was not effective in healing of third degree burns [22]. We think the reason is due to Pseudomonas aeruginosa infection of wounds.

Histological findings showed that G. glabra decreased acute inflammation in the treated groups. Gly and GA with downregulate expression of inflammatory mediators such as interleukin could be effective in inflammatory diseases [37]. In the inflammation phase of wound healing process, macrophages and neutrophils in the wound bed release inflammatory mediators, such as tumor necrosis factor alpha (TNF-a) and interleukin-1 (IL-1). On the other hand, TNF-a induce production of Matrix metalloproteinase-9 (MMP-9) in keratinocytes [38]. Expression and activity of MMP9, as a protease responsible for the degradation of matrix, can be inhibited by glabridin [39]. 
Histopathological observations confirm increased neovessels in the G. glabra and phenytoin treated groups ( $\mathrm{P}<0.01$ and $\mathrm{P}<0.05$, respectively). Sufficient blood circulation is one of the important factors in wound healing [40]. Neovascularization increases oxygen levels and promotes cell proliferation and collagen synthesis [40]. In this study, the effects of G. glabra are clearly seen in neovascularization. In histopathological examination, sections of treated groups were showed neovascularization at a much higher level in compared to the control group. According to the Aly et al study, G.glabra promote wound healing through increasing angiogenesis, reepithelialization and wound contraction [41]. Our study was consistent with other study [42].

\section{CONCLUSION}

The herbal creams of G. glabra significantly increased collagen content and the rate of epithelialization and also reduced the severity of inflammation. The extract of G. glabra which contains the various types of bioactive compounds, could be used effectively in dermal wound healing and as a candidate for treatment of acute wounds. More studies with more different doses of the G. glabra extract are recommend.

\section{MATERIALS AND METHODS}

\subsection{Plant material and extraction}

The roots of Glycyrrhiza glabra L. were purchased from Grand Bazzar, Tehran, Iran. A voucher specimen (E1-75-1111) was deposited at the herbarium of the Faculty of Pharmacy, Mazandaran University of Medical Science, Sari, Iran.

The roots were powdered and extracted with $\% 80$ ethanol by maceration at room temperature. The extract was concentrated using a rotary evaporator at $40^{\circ} \mathrm{C}$ and dried by a freeze dryer.

\subsection{Determination of total phenolic and flavonoid contents}

Total phenolic content of the hydroalcoholic extract was determined by Folin Ciocalteu method [43]. Calibration curve was plotted using various concentrations of gallic acid $(12.5,25,50,100,200 \mu \mathrm{g} / \mathrm{ml})$. The total phenolic content was expressed as milligrams of gallic acid equivalents per gram of extract. The total flavonoid content was estimated using aluminium chloride colorimetric assay [44]. Quercetin $(10,12.5,25,50$, $100,200 \mu \mathrm{g} / \mathrm{ml}$ ) was used to make calibration curve and flavonoid content was expressed as milligrams of quercetin equivalents per gram of extract.

\subsection{Herbal cream preprations}

Herbal creams $(5,10 \% \mathrm{w} / \mathrm{w})$ were prepared by mixing accurately weighed dried extract of G. glabra (5 and $10 \mathrm{~g}$, respectively) to cream base by levigation method using glycerin ( 5 and $10 \mathrm{~g}$, respectively) as levigating agent to prepare a smooth paste, gradually incorporating more cream base until to form homogeneous cream, finally transferred in a suitable container.

\subsection{Animal studies}

Eight male guinea pigs, weighing 700-800 g were used in this study. All experiments were performed after getting permission from Animal Ethics Committee of Mazandaran University (code 2457). Instructions regarding the care and use of laboratory animals were completely followed. A week before the test, the animals were transported to the laboratory for acclimatize. They were kept in a separate cage in a room under standard conditions, $25 \pm 1^{\circ} \mathrm{C}$ room temperature, $12 \mathrm{~h} \mathrm{light/dark} \mathrm{cycles.} \mathrm{Animals} \mathrm{had} \mathrm{free} \mathrm{access} \mathrm{to} \mathrm{food} \mathrm{and} \mathrm{water.}$

\subsection{Create acute wound model}

Excision wound was created according to a previous study [45]. After anesthesia with ketamine (50 $\mathrm{mg} / \mathrm{kg}$ ) and xylazine $(5 \mathrm{mg} / \mathrm{kg})$, all of guinea pigs were shaved on the dorsal surface of lumbar area with electric shaver. The shaved area was disinfected with alcohol $70 \%$ and four square full-thickness wounds in lumbar area was created with dimensions of $1.5 \times 1.5$ by surgical blade in each guinea pig. The wounds were randomly classified into 4 groups, with 7 wounds in each group Figure 6. 


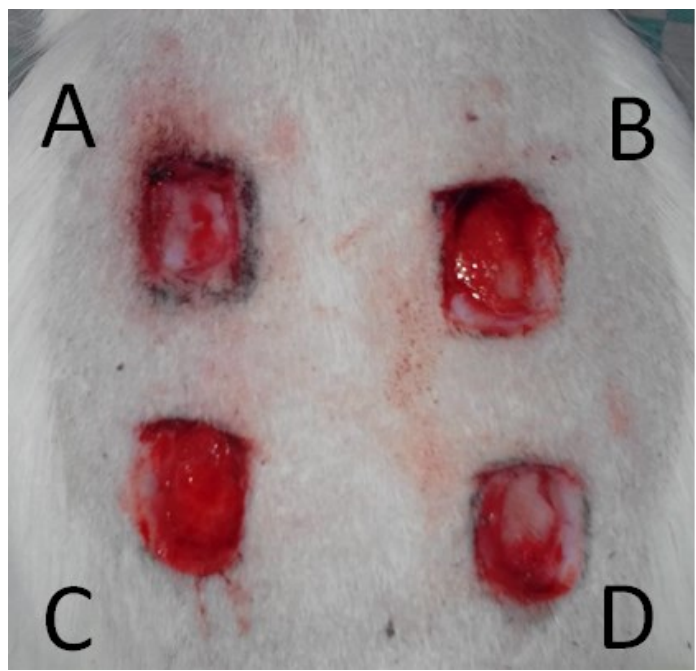

Figure 6: Acute full thickness wound model. Four square full-thickness wounds on the dorsal surface of lumbar area.

\subsection{Studied groups}

Immediately after surgery, the wounds were randomly divided into four groups.

Group 1: negative control, the full thickness wounds was not treated anything.

Group 2: positive control, the full thickness wound was treated with $1 \%$ phenytoin cream.

Group 3: the full thickness wound was treated with 5\% w/w G. glabra cream.

Group 4: the full thickness wound was treated with $10 \%$ w/w G. glabra cream.

The phenytoin and formulated G. glabra extract cream were applied once daily from the day of the operation until 12 days after surgery. The wounds were uncovered during the whole the experimental period. The animals were kept separately in steel cages. The animal cages cleaned daily to prevent secondary infection.

\subsection{Wound healing rate determination}

On days 3, 5, 7, 9 and 12, was measured the rate of wound healing (WHR). For measuring the area, the wound was covered with a transparent sheet and then draw around the wound. Wound healing rate determination was calculated using the following formula:

WHR $(\%)=[(\mathrm{Wo}-\mathrm{Wu}) / \mathrm{Wo}] \times 100$

Wo: Original wound area; Wu: Unhealed wound area.

\subsection{Histological evaluation}

In addition to the recording macroscopic properties of the wound, fixed skin tissue samples were examined by light microscopy for histological evaluation. To separate the biopsy specimen, $5 \mathrm{~mm}$ margin of healthy skin around the edges of the healed wound were collected from each wound. The samples were fixed in $10 \%$ formalin and then the preparation steps tissue is done automatically by the processor tissue system. After embedding in paraffin, 5-microns thick sections were provided. Slides stained by using hematoxylin and eosin using the standard protocol. The histological image were assessed according to the Abramov score method [46]. Histological score of criteria wound healing were scored as: Acute inflammation grading were scored as: 0:None, 1:Scant, 2:Moderate, 3:Abundant, Granulation tissue fibroblast maturation grading were scored as: 0:Immature, 1:Mild maturation, 2:Moderate maturation, 3:Fully maturate, Collagen deposition grading were scored as: 0:None, 1:Scant, 2:Moderate, 3:Abundant, Epidermis formation grading were scored as 0:None, 1:Partial, 2:Complete but immature or thin, 3:Compelete and mature, Neovascularization grading were scored as: 0:None, 1:Up to five vessels per high-power field (HPF), 2:6-10 vessels per HPF, 3:More than 10 vessels per HPF, and Keratin layer formation grading were scored as: 0:None, 1:Partial, 2:Complete but immature or thin, 3:Compelete and mature. 


\subsection{Collagen assessment}

12 days after surgery, skin samples stained by using Trichrome Masson staining to determine the content of collagen. For the semi-quantitative analysis, photomicrographs were evaluated by densitometry using MacBiophotonics Image J 1.41a software. The blue color severity of collagen fibers was assessed as the ratio of the stained area to the entire field assessment

\subsection{Data analysis}

Quantitative data were assessed in all groups, with software spss, version 15. All data were expressed by test of One-Way ANOVA and Tukey. Significant differences between groups were analyzed and P $<0.05$ was considered significant.

Acknowledgements: This research was supported by Molecular and Cell Biology Research Center, Faculty of Medicine, Mazandaran University of Medical Sciences, Sari, Iran (grant\# IR.MAZUMS.REC.1395.2457).

Author contributions: Concept - F.T.A.; Design - F.T.A.; Supervision - F.T.A., A.K.M., S.S, R.E., M.G.; Resource - F.T.A.; Materials - F.T.A., S.S., R.E.; Data Collection and/or Processing - S.H.,; Analysis and/or Interpretation - F.T.A.; Literature Search - F.T.A., S.S.; Writing - F.T.A., S.S.; Critical Reviews - F.T.A., S.S, N.H., R.E.A., K.M.

Conflict of interest statement: There is no conflict of interest in this study and publication.

\section{REFERENCES}

[1] Ghabaee DNZ, Ebrahimzadeh MA, Akbari J, Amiri FT. Wound healing activity of Sambucus ebulus. Int J Pharm Sci Res. 2017;8(1):132-135.

[2] Singh K, Agrawal NK, Gupta SK, Sinha P, Singh K. Increased expression of TLR9 associated with pro-inflammatory S100A8 and IL-8 in diabetic wounds could lead to unresolved inflammation in type 2 diabetes mellitus (T2DM) cases with impaired wound healing. J Diabetes Complications.2016;30(1):99-108.

[3] Singh A, Halder S, Chumber S, Misra MC, Sharma LK, Srivastava A, Menon GR. Meta-analysis of randomized controlled trials on hydrocolloid occlusive dressing versus conventional gauze dressing in the healing of chronic wounds. Asian J Surg. 2004;27(4):326-332.

[4] Mahmoudi RM, Talebpour AF, Mirhoseini M, Ghasemi M, Mirzaei M, Mosaffa N. Application of allogeneic fibroblast cultured on acellular amniotic membrane for full-thickness wound healing in rats. Wounds. 2016; 28(1): 14-19.

[5] Doersch KM, DelloStritto DJ, Newell-Rogers MK. The contribution of interleukin-2 to effective wound healing. Exp Biol Med (Maywood). 2017;242(4):384-396.

[6] Pazyar N, Yaghoobi R, Rafiee E, Mehrabian A, Feily A. Skin wound healing and phytomedicine: a review. Skin Pharmacol Physiol. 2014;27(6):303-310.

[7] Dorjsembe B, Lee HJ, Kim M, Dulamjav B, Jigjid T, Nho CW. Achillea asiatica extract and its active compounds induce cutaneous wound healing. J Ethnopharmacol. 2017;206:306-314.

[8] dos Santos Gramma LS, Marques FM, Vittorazzi C, de Andrade TAM, Frade MAC, de Andrade TU, Endringer DC, Scherer R, Fronza M . Struthanthus vulgaris ointment prevents an over expression of inflammatory response and accelerates the cutaneous wound healing. J Ethnopharmacol. 2016;190:319-327.

[9] Komes D, Belščak-Cvitanović A, Jurić S, Bušić A, Vojvodić A, Durgo K. Consumer acceptability of liquorice root (Glycyrrhiza glabra L.) as an alternative sweetener and correlation with its bioactive content and biological activity. Int J Food Sci Nutr. 2016;67(1):53-66.

[10] Jeon J-S, Kim H-T, Kim M-G, Oh M-S, Hong S-R, Yoon M-H, Shin H-S, Shim J-H, Afifi NA, Hacimuftuoglu A, Aty AMAE. Simultaneous detection of Glabridin, (-)-a-Bisabolol, and Ascorbyl tetraisopalmitate in whitening cosmetic creams using HPLC-PAD. Chromatographia. 2016;79(13-14):851-860.

[11] Sharma H, Yunus G, Agrawal R, Kalra M, Verma S, Bhattar S. Antifungal efficacy of three medicinal plants Glycyrrhiza glabra, Ficus religiosa, and Plantago major against oral Candida albicans: A comparative analysis. Indian J Dent Res. 2016;27(4):433-436.

[12] Sharma H, Yunus G, Mohapatra AK, Kulshrestha R, Agrawal R, Kalra M. Antimicrobial efficacy of three medicinal plants Glycyrrhiza glabra, Ficus religiosa, and Plantago major on inhibiting primary plaque colonizers and periodontal pathogens: An in vitro study. Indian J Dent Res. 2016;27(2):200-204. 
[13] Fukuchi K, Okudaira N, Adachi K, Odai-Ide R, Watanabe S, Ohno H, Yamamoto M, Kanamoto T, Terakubo S , Nakashima H, Uesawa Y, Kagaya H , Sakagami H. Antiviral and antitumor activity of Licorice root extracts. In Vivo. 2016;30(6):777-785.

[14] Tanideh N, Rokhsari P, Mehrabani D, Mohammadi Samani S, Sabet Sarvestani F, Ashraf MJ, Hosseinabadi O $\mathrm{K}$, Shamsian S, Ahmadi N. The healing effect of licorice on Pseudomonas aeruginosa infected burn wounds in experimental rat model. World J Plast Surg. 2014;3(2):99-106.

[15] Tanaka A, Horiuchi M, Umano K, Shibamoto T. Antioxidant and anti-inflammatory activities of water distillate and its dichloromethane extract from licorice root (Glycyrrhiza uralensis) and chemical composition of dichloromethane extract. J Sci Food Agri. 2008;88(7):1158-1165.

[16] Chen X, Fang D, Li L, Chen L, Li Q, Gong F, Fang M. Glycyrrhizin ameliorates experimental colitis through attenuating interleukin-17-producing $\mathrm{T}$ cell responses via regulating antigen-presenting cells. Immunol Res. 2017;65(3):666-680.

[17] Asl MN, Hosseinzadeh H. Review of pharmacological effects of Glycyrrhiza sp. and its bioactive compounds. Phytother Res. 2008;22(6):709-724.

[18] Simmler C, Pauli GF, Chen S-N. Phytochemistry and biological properties of glabridin. Fitoterapia . 2013;90:160-184.

[19] Oloumi MM, Derakhshanfar A, Nikpoor A. Healing potential of liquorice root extract on dermal wounds in rats. J Vet Res. 2007;62(4):147-154.

[20] Memariani Z, Hajimahmoodi M, Minaee B, Khodagholi F, Yans A, Rahimi R, , Amin G, Moghaddam G, Toliyat T, Sharifzadeh M. Protective effect of a polyherbal traditional formula consisting of Rosa damascena Mill., Glycyrrhiza glabra L. and Nardostachys jatamansi DC., against ethanol-induced gastric ulcer. Iran J Pharm Res. 2017;16(2):694-707.

[21] Najeeb VD, Al-Refai AS. Antibacterial effect and healing potential of topically applied licorice root extract on experimentally induced oral wounds in rabbits. Saudi J Oral Sci. 2015;2(1):10-13.

[22] Tanideh N, Rokhsari P, Mehrabani D, Mohammadi Samani S, Sabet Sarvestani F, Ashraf MJ, Hosseinabadi OK, Shamsian S, Ahmadi N. The healing effect of licorice on Pseudomonas aeruginosa infected burn wounds in experimental rat model. World J Plast Surg . 2014;3(2):99-106.

[23] Alhusein N, Blagbrough IS, Beeton ML, Bolhuis A, Paul A. Electrospun zein/PCL fibrous matrices release tetracycline in a controlled manner, killing Staphylococcus aureus both in biofilms and ex vivo on pig skin, and are compatible with human skin cells. Pharm Res. 2016;33(1):237-246.

[24] Francis NK, Pawar HS, Peter N, Biswas G, Majumdar J, Mitra A. Evaluation of wound healing and antimicrobial physiognomies of alcoholic extract of Ocimum sanctum (basil) in diabetic rabbit model. Int J Herb Med. 2017;5(2):9197.

[25] Getie M, Gebre-Mariam T, Rietz R, Neubert R. Evaluation of the release profiles of flavonoids from topical formulations of the crude extract of the leaves of Dodonea viscosa (Sapindaceae). Pharmazie . 2002;57(5):320-322.

[26] Xue M, Jackson CJ. Extracellular matrix reorganization during wound healing and its impact on abnormal scarring. Adv Wound Care (New Rochelle). 2015;4(3):119-136.

[27] Lodhi S, Jain A, Jain AP, Pawar RS, Singhai AK. Effects of flavonoids from Martynia annua and Tephrosia purpurea on cutaneous wound healing. Avicenna J Phytomed. 2016;6(5):578-591.

[28] Oliveira RN, Mancini MC, Oliveira FCSd, Passos TM, Quilty B, Thiré RMdSM, McGuinness GB. FTIR analysis and quantification of phenols and flavonoids of five commercially available plants extracts used in wound healing. Matéria (Rio J.). 2016;21(3):767-779.

[29] Hasamnis AA, Mohanty BK, Patil S. Evaluation of wound healing effect of topical phenytoin on excisional wound in albino rats. J Young Pharm. 2010;2(1):59-62.

[30] Mantovani A, Allavena P, Sica A, Balkwill F. Cancer-related inflammation. Nature. 2008; 454(7203): 436-444.

[31] Loni F, Maghsodi H, Shiri S. The effect of Glycirrhiza glabra on osteoarthritis: suppression of TNF-a, IL-1b, Cox-2, iNOS gene expression and prostaglandin E2 and nitric oxide production in chondrocytes and monocyte/macrophages. Healt Biotech Biopharma. 2017;1(2): 70-82.

[32] Lim HS, Yo SR, Lee MY, Seo CS, Shin HK, Jeong SJ. Potential inhibitory effects of the traditional herbal prescription Hyangsosan against skin inflammation via inhibition of chemokine production and inactivation of STAT1 in HaCaT keratinocytes. Mol Med Rep. 2017; 2515-2522.

[33] Okda FA, Yassein S, Ahmed AR, Soufy H, Nasr SM. Some haematological and biochemical investigations on duck virus hepatitis following administration of glycyrrhizin. ISRN Pharmacol. 2013;2013: 849471.. 
[34] Castangia I, Caddeo C, Manca ML, Casu L, Latorre AC, Díez-Sales O, Saurí AR, Bacchetta G, Fadda AM, Manconi M. Delivery of liquorice extract by liposomes and hyalurosomes to protect the skin against oxidative stress injuries. Carbohydr Polym. 2015;134:657-663.

[35] Shen L, Cui Z, Lin Y, Wang S, Zheng D, Tan Q. Anti-inflammative effect of glycyrrhizin on rat thermal injury via inhibition of high-mobility group box 1 protein. Burns. 2015;41(2):372-378.

[36] Andersson U, Tracey KJ. HMGB1 is a therapeutic target for sterile inflammation and infection. Annu Rev Immunol. 2011;29:139-162.

[37] Matsui S, Matsumoto H, Sonoda Y, Ando K, Aizu-Yokota E, Sato T, Kasahara T . Glycyrrhizin and related compounds down-regulate production of inflammatory chemokines IL-8 and eotaxin 1 in a human lung fibroblast cell line. Int Immunopharmacol. 2004;4(13):1633-1644.

[38] Majtan J, Bohova J, Garcia-Villalba R, Tomas-Barberan FA, Madakova Z, Majtan T, Majtan V, Klaudiny J. Fir honeydew honey flavonoids inhibit TNF-a-induced MMP-9 expression in human keratinocytes: a new action of honey in wound healing. Arch Dermatol Res. 2013;305(7):619-627.

[39] Hsieh MJ, Lin CW, Yang SF, Chen MK, Chiou HL. Glabridin inhibits migration and invasion by transcriptional inhibition of matrix metalloproteinase 9 through modulation of NF-KB and AP-1 activity in human liver cancer cells. Br J Pharmacol. 2014;171(12):3037-3050.

[40] Cetin E, Yesil-Celiktas O, Cavusoglu T, Demirel-Sezer E, Akdemir O, Uyanikgil Y. Incision wound healing activity of pine bark extract containing topical formulations: A study with histopathological and biochemical analyses in albino rats. Int J Pharm Sci. 2013;68(1):75-80.

[41] Aly UF, Mansour HF. Novel Pharmaceutical gels containing glyccerihizic acid ammonium salt for chronic wounds. Br J Pharm Res. 2014;4(5):654-668.

[42] Bahramsoltani R, Farzaei MH, Rahimi R. Medicinal plants and their natural components as future drugs for the treatment of burn wounds: an integrative review. Arch Dermatol Res. 2014;306(7):601-617.

[43] Miliauskas G, Venskutonis P, Van Beek T. Screening of radical scavenging activity of some medicinal and aromatic plant extracts. Food Chem. 2004;85(2):231-237.

[44] Silva MCAd, Paiva SR. Antioxidant activity and flavonoid content of Clusia fluminensis Planch. \& Triana. An Acad Bras Cienc 2012;84(3):609-616.

[45] Amiri FT, Fathabadi FF, Rad MM, Piryae A, Ghasemi A, Khalilian A, Yeganeh F, Mosaffa N. The effects of insulinlike growth factor-1 gene therapy and cell transplantation on rat acute wound model. Iran Red Crescent Med J. 2014;16(10):e16323.

[46] Abramov Y, Golden B, Sullivan M, Botros SM, Miller JJR, Alshahrour A, Goldberg RP, Sand PK. Histologic characterization of vaginal vs. abdominal surgical wound healing in a rabbit model. Wound Rep Reg. 2007;15(1):8086. 